\title{
Effectiveness of the Augmented Reality on Improving the Visual Thinking in Mathematics and Academic Motivation for Middle School Students
}

\author{
Sabah Abdalla Elsayed ${ }^{1 *}$, Hamda Ibrahim Al-Najrani ${ }^{1}$ \\ ${ }^{1}$ Curriculum and Instruction Department, College of Education, Imam Abdulrahman Bin Faisal University, Dammam, SAUDI \\ ARABIA
}

Received 18 February 2021 - Accepted 8 June 2021

\begin{abstract}
This research aimed to identify the effectiveness of augmented reality technology on improving visual thinking in mathematics and academic motivation among middle school learners in Saudi Arabia. To accomplish the research objectives, the experimental method with a quasiexperimental design was adopted and it included an experimental group and a control group with the pre-and post-test of both groups. The research was implemented on a random sample of (76) students and the research tools included the Visual Thinking Test and Academic Motivation Scale. The tools were pre-and post-tested to the groups of the research in the second semester of the academic year 2019/2020AD. The results concluded that the experimental group surpassed the control group in visual thinking and academic motivation. Based on the results, both researchers recommended the involvement of augmented reality technology in mathematics instruction at different levels of education. They also recommend the inclusion of this technology in mathematics in overall, and Geometry in specific.
\end{abstract}

Keywords: academic motivation, augmented reality, middle school, mathematics, visual thinking

\section{INTRODUCTION}

The massive transformation in communications and information technology imposes on education the need to adopt new methods of education based on methodological foundations compatible with contemporary technology. The use of technology in education has become an urgent and absolute need not just a choice as conventional education is no longer appropriate for the new generations. This is illustrated by the connection of students to their tablets, cell phones, and other technical advancements. Thus, many teaching techniques have emerged that rely on applying digital technology in education.

Most countries have tended to develop their curricula as the concern in the development started at all educational stages, and specialists needed to develop strategies and activities for the curriculum, by employing modern technologies in education (Alimat \& Abu Jalalah, 2011). The Ministry of Education has therefore initiated the curriculum development and educational environment improvement and the use of technology within the Education Initiative objectives to fulfill the National Transformation Program 2020, which is one of the Saudi Vision 2030 programs to improve the outcomes of the educational process (The Ministry of Education, 2016).

Augmented Reality (AR) technologies are among the contemporary and significant concepts added by information technology, which refers to the inclusion of reality with virtual reality within specific educational situations through special methods and techniques (Nofal, 2010). Augmented reality is distinguished as a type of technology that improves the physical world through computer-generated content. Also, augmented reality allows the incorporation of digital content effortlessly to realize the user insight of the physical world, as it is possible to add 2D and 3D forms and incorporate audio, video, and text files. These tools can also increase personal skill and information and realize what is going on around them (Yuen et al., 2011).

Shelton (2002) stated that using augmented reality technology, actual and virtual objects can be combined, and the use of suitable knowledge from the external

(c) 2021 by the authors; licensee Modestum. This article is an open access article distributed under the terms and conditions of the Creative Commons Attribution License (http://creativecommons.org/licenses/by/4.0/). 


\section{Contribution to the literature}

- It offers quantitative statistics and data for the effectiveness of the augmented reality on improving the visual thinking in mathematics and academic motivation for middle school students.

- The results suggest that concentrating on the use of the augmented reality technology in teaching mathematics for middle school students due to its effective role in inspiring students and raising their visual thinking skills.

- It presents situations from the employment of the augmented reality for teaching mathematics and developing students' visual thinking.

environment in a digital sphere that stimulates reality can be possible. Moreover, modern applications of technology in augmented reality make it possible to connect the fields of instruction and entertainment, and thus to find new methods and resources to facilitate teaching and learning.

The National Council of Teachers of Mathematics (NCTM) in the United States of America (2008) enacted the principles and standards of school mathematics and introduced technology as a basic tool for mathematics instruction in the 21st century, which emphasized the significance of augmented reality technologies. All mathematics teacher must exploit the role of technology in improving a student's understanding of mathematics and developing his or her mathematical knowledge. Besides, learners can think about the use of technology to solve issues they have not faced before.

Augmented reality technology aims to incorporate the actual environment in the computer and promoting it with virtual data, resulting in the student's incorporation between the real situation in front of him/her and the virtual situation generated by the computer, which, in turn, enhances the real situation with additional information. It targets to design a system in which the change between the physical world and what has been inserted to it cannot be realized, by augmented reality technology. When the student uses this technology to think over his surrounding environment, the objects in this environment are provided with information that goes along with the image he is thinking over or provided with a 3D shape that can be controlled while presented on the screen. Augmented reality technology also helps tremendously to inspire learners and make the learning experience more fun (Rattanarungrot et al., 2014).

Numerous studies, including Estapa and Nadolny (2015), Hsiao et al. (2016), and Bacca et al. (2014) have highlighted the need to build and develop multiple scenarios for the use of augmented reality technology in teaching and learning at all stages of education. It helps to improve student learning and can stimulate motivation for learners. Barreira et al. (2012) also suggested that learners who were exposed to the experience of augmented reality had more fun and less challenging study experiences than those who relied solely on conventional methods to teach them. The augmented reality technology has several advantages, among them: its ability to encourage motor learning and support the learning process with a wide range of digital learning elements that help integrate learners into the learning process, and increase their motivation towards learning (Diaza et al., 2015).

\section{Research Problem}

Recently, the various aspects of life, including technological advancement and scientific progress, are constantly and rapidly evolving, and due to the significance of technology and its role in curriculum development, educational institutions around the world have shown interest in teaching through modern applications and in training their use in the educational process. Applications of augmented reality technology that can be used in the educational process have arisen as a result of this technological growth. It helps learners to access digital information that is not available in reality. Both researchers noticed a deficiency in the degree of different higher-order thinking abilities enjoyed by middle school learners for multiple reasons including the conventional education, the limited use of recent technology and its utilization in various instructional situations by teachers, and the shortage of teachers' experience in utilizing current applications and technologies in education. To verify the research problem, the two researchers prepared a pilot study by conducting some interviews with the mathematics supervisors, and asked them several questions, namely:

1. From your field visit observations, do the teachers have prior knowledge of augmented reality technology?

2. Did you notice during the field visit that the teachers use augmented reality technology while teaching?

3. If teachers use augmented reality technology during their teaching, what are the challenges they are facing?

4. Can augmented reality improve teachers' performance?

5. From your math lessons' observations, does the teacher use activities that help develop visual thinking skills? Clarify your examples if the answer is (Yes). 
The pilot study revealed the existence of a deficiency in the reality of teaching mathematics to middle school learners. The answers of the supervisors indicated their use of the conventional method in teaching mathematics in middle school, which depends on the very limited use of some educational methods, in addition to the lack of interest in placing learners in the learning environment in which they can participate, be active, and learn by practice, as the teacher pays full attention to the content, regardless of the method used in teaching. Further, teachers of mathematics are only interested in gathering facts and concepts without being interested in developing abilities to think, particularly visual thinking among learners, and there is no concern about the targeted emotional aspects of teaching mathematics that help learners achieve learning.

Besides, when checking the follow-up archives of some middle school learners, both researchers noted that the mean scores of learners who have been taught in the conventional way have not been well estimated compared to those taught by modern teaching ways. This gap needs to be addressed by examining the effect of the shift from the conventional teaching way to the more technical way.

Therefore, the research problem was determined based on the existence of a deficiency or weakness in visual thinking skills among middle school learners, in addition to the existence of a weak level of achievement motivation among them. There is also a deficiency in the use of educational methods and computers in teaching some aspects of mathematical knowledge that are difficult to harmonize in reality. To address this problem, there is a need to use augmented reality technology, which is one of the technologies that can participate to the development of visual thinking and enhance academic motivation.

Therefore, this research tries to reply the following prime question:

What is the effectiveness of augmented reality technology on improving visual thinking skills in mathematics and academic motivation among middle school students?

From this prime question, several sub-questions branched:

1. What is the effectiveness of augmented reality technology on improving visual thinking skills in mathematics among second-grade middle school students?

2. What is the effectiveness of augmented reality technology on improving academic motivation among second-grade middle school students?

\section{Research Objectives}

1. There is a statistically significant difference between the mean scores of the experimental group students (who studied using the augmented reality technology) and the control group's scores (who studied using the conventional method) in the visual thinking test.

2. There is no statistically significant difference between the mean scores of the experimental group in the post and follow up visual thinking test (two months after the completion of the application of the research experiment).

3. There is a statistically significant difference between the mean scores of the experimental group students (who studied using the augmented reality technology) and the control group's scores (who studied using the conventional method) in the academic motivation scale.

4. There is no statistically significant difference between the mean scores of the experimental group in the post and follow up academic achievement scale (two months after the completion of the application of the research experiment).

\section{Research Hypotheses}

1. There is a statistically significant difference between the mean scores of the experimental group students (who studied using the augmented reality technology) and the control group's scores (who studied using the conventional method) in the visual thinking test.

2. There is no statistically significant difference between the mean scores of the experimental group in the post and follow up visual thinking test (two months after the completion of the application of the research experiment).

3. There is a statistically significant difference between the mean scores of the experimental group students (who studied using the augmented reality technology) and the control group's scores (who studied using the conventional method) in the academic motivation scale.

4. There is no statistically significant difference between the mean scores of the experimental group in the post and follow up academic achievement scale (two months after the completion of the application of the research experiment).

\section{Research Significance}

Theoretical Significance: the research contributed to enriching the scientific references on the use of augmented reality technology in teaching mathematics and keeping pace with the modern trends of the Saudi Vision 2030 that calls for employing modern technology in education because it adopts a recent instruction way 
depends on the learners' interaction with the augmented reality technology, making the learning environment more dynamic and active, which reflects positively on the learners' thinking and motivation for learning.

Practical Significance: First: The results will be valuable for those participating in mathematics teaching including supervisors, teachers, and researchers in particular. They also help to plan the mathematics curriculum by taking into consideration the use of augmented reality technology in mathematics for the middle stage, guaranteeing the enrichment of mathematics subjects.

Second: The results will be valuable to learners because it will inspire them to carry out active learning through interaction with the augmented reality technology, and create motivation to learn, which is positively reflected in their mathematics learning.

Third: The results will extend researchers with field evidences about the effectiveness of augmented reality technology in improving visual thinking and learning motivation, and the continuing impact of learning on learners.

Fourth: This research maintains pace with worldwide and local developments that call for the need to benefit from the use of augmented reality technologies in schooling.

\section{Research Limits}

Objective Limits: This research was limited to the sixth chapter (Measurement: Area and Volume) of the mathematics book for the second-grade learners in the second semester in middle school, and the visual thinking skills that include: visual discrimination, visual perception, third dimension perception, spatial visualization, and visual analysis of shapes; while the academic motivation dimensions were: ambition, perseverance, enjoying learning mathematics. Augmented reality apps were deployed and they were: Zappar - HP Reveal.

Human Limits: The research was implemented to (76) second-grade learners in public middle schools in Al-Khobar governorate, and the learners were divided into two groups: one experimental group consisting of (38) learners, and a control group consisting of (38) learners.

Spatial Limits: This research was implemented in middle schools in Al-Khobar Governorate - Eastern Province - Kingdom of Saudi Arabia.

Time Limits: The research was implemented during the second semester of the 2019/2020 academic year.

\section{Research Terminology}

Augmented Reality Technology: Larsen et al. (2011) defined it as gathering, synthesizing, and visualizing digital data using digital views of the reality of the environment surrounding humans, and from a technological perspective, augmented reality is often linked with computers or smart devices that can be carried.

Procedurally, it is defined in this research as a form of technology such as (Zappar - HP Reveal) used in teaching mathematics among middle school secondgrade learners, through which digital content is added to the mathematical content to provide learners with additional information that is not directly apparent upon seeing that content to improve their visual thinking and academic motivation.

Visual Thinking: Muhammad (2016) defined visual thinking skills as a structure of processes containing of a group of skills that inspire the student to visual thinking and meditation, and to interpret these images into the languages of his concept; written or spoken, and extract information from them.

Procedurally, it is defined in this research as a sequence of mental processes that treat what is seen by the second-grade student from images and drawings to be able to obtain meaningful information. The student then has a visual image in mind that is measured by the visual thinking test developed by the researchers, which measures the skills of visual discrimination, visual perception, third dimension perception, spatial visualization, and visual analysis of shapes.

Academic Motivation is defined by Al Laqani and Al-Jamal (2013) as the level of conviction of the individual in the importance of the program he/ she studies, which affects his level of performance during the study, and needs him to progress towards the specific goals of the program.

Procedurally, it is defined in this research as the willingness of the second-grade student to perform the activities assigned to her by the teacher and it is determined by the total scores that the student will obtain in her response to the academic motivation scale prepared by the researchers in the following dimensions: ambition, perseverance, enjoying learning mathematics.

\section{THEORETICAL FRAMEWORK AND PREVIOUS STUDIES}

\section{Augmented Reality Technology}

Azuma (1997) defined the augmented reality technology as interactive technology, in which a part of the virtual world is incorporated with the real world, and 3D shapes are added to it.

Yuen et al. (2011) noted that augmented reality is a type of technology that enriches the actual world through computer-generated content, as it allows seamless adding of digital content to comprehend the user's insight of the actual world, also, 2D and 3D forms can be supplemented, and text, audio, and video files 

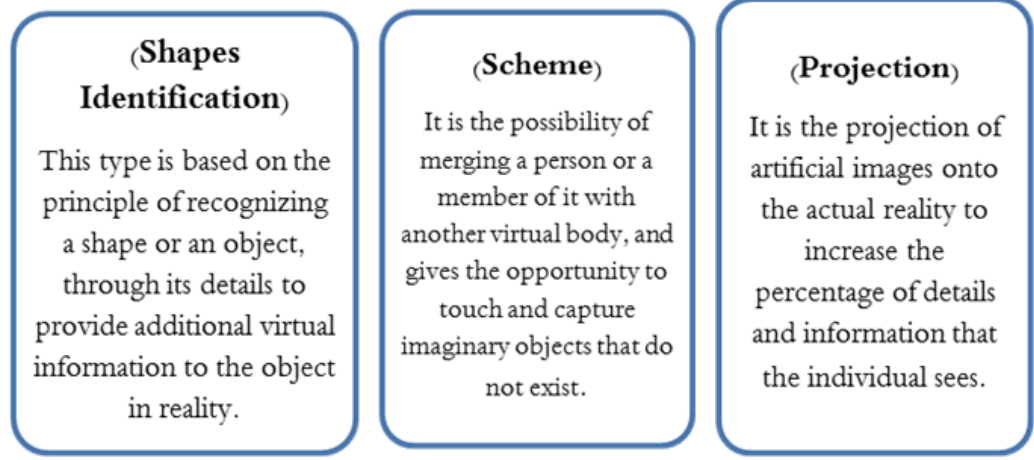

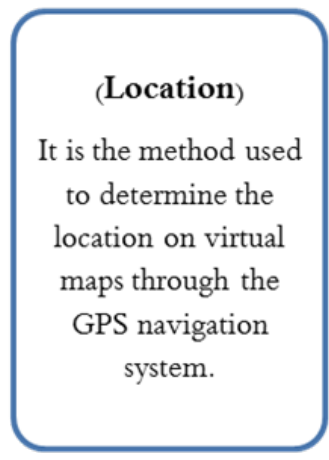

Figure 1. Types of augmented reality

inserted. These tools can also increase persons' knowledge and perception of what is going on around them. Besides, augmented reality is a technology that provides an infinite number of auxiliary tools for receiving education, enhances the study material, makes it interesting and attractive, mixes real reality with virtual objects, and transfers the learner from the recipient to the information seeker.

Hence, the use of augmented reality technology in education and the classroom environment has many advantages. Anderson and Liarokapis (2010) mentioned that one of the advantages of augmented reality technology is that it provides the teacher with clear and concise information that enables him to enter his information and data and communicate with it in an easy way that allows interaction between the teacher and the learner. It also has the advantage of being able to expand easily and make the procedures between teacher and learner clear.

Also, one of the advantages of augmented reality technology is mixing imagination and reality in a real environment by using interactive $3 \mathrm{D}$ objects at the same time when using it (Azuma et al., 2001). This technology also provides educational content on multiple dimensions from a $2 \mathrm{D}$ and $3 \mathrm{D}$ perspective. It enables interaction with 2D and 3D manufactured objects in a blended augmented reality (Kerawalla et al., 2006), and allows learners to experience phenomena that are not possible to occur in the real world (Klopfer \& Squire, 2008). This technique is also characterized by improved learning, development of motivation, and cooperation among learners (Bacca et al., 2014; Lee, 2012).

Yuen et al. (2011) also indicated the justifications for using augmented reality technology as follows: it stimulates learners to discover information on their own, provides a learning environment suitable for multiple learning styles and different ages, helps in learning study materials that the learner cannot easily perceive except through realistic experiences such as astronomy and geography, and encourages the learner and increases his creativity and his ability to imagine and perceive.
Ahmad (2020) also mentioned that the benefits of augmented reality technology in mathematics learning are that this technology increases learners' confidence and understanding. It contributes to increased understanding of mathematics content, in particular learning geometry and $3 \mathrm{D}$ shape. The augmented reality technology improves the geometry visualization of learners by providing interesting and entertaining visual content to see engineering objects from different angles and this made learning mathematics more effective.

Glockner et al. (2014) stated that for augmented reality to be possible, several basic tasks must be accomplished and their outcomes combined effectively:

1. Image splitting: It is the process of separating the front end of the objects from their background, and the degree of quality of the separation process determines the success of the process of extracting objects from the image.

2. Extraction: it means finding the known elements in the image from corners, lines, curves, and shapes, and this step consists of several stages; you start with exploring the corners, then the edges, and finally, uncovering the square of the mark.

3. Mark exploration: The true mark must be designed in a way that makes it easy to explore to make it easy to identify it among other marks, and this stage is concerned with finding the location of each cell on the image.

4. Camera Orientation: This step comes after identifying the mark, as the location of the mark is located within the spatial space for digital objects to be embodied on the image, and their scale and direction must match the detected mark i.e. the digital object representing the image appears and not another object.

5. Integration: At this stage, 3D objects are embodied within the scene, and their inclusion on the mark takes into account the quality of rendering and lighting.

There are different types of augmented reality reported by Patkar et al. (2013), and they are summarized in Figure 1. 
This means that augmented reality (AR) presents virtual objects to the actual environment to improve the environment, and the augmented environment is derived from the overloading of computer-generated objects and information on physical objects. Augmented reality is widely used for learning purposes. Augmented reality-based learning contains a diversity of applications targeting culture, history, games, sightseeing, and museum guidance (Baker et al., 2020; Ivanova \& Ivanov, 2011).

The effectiveness of teaching with augmented reality is evident. The studies of Cai et al. (2020), Perez-Lopez and Contero (2013), Liou et al. (2017) that augmented reality is a hopeful tool to develop students' motivation, to reinforce the teaching and learning process, and to encourage students to pursue tasks. Also, augmented reality technology helps to comprehend various thoughts in the computer graphics field, enhance perception, support thinking, and develop positive trends towards learning mathematics.

\section{Visual Thinking}

Visual thinking is a mental activity and skill that helps a person obtain information, represent it, interpret it, perceive it and memorize it, then express it and his ideas visually and verbally. This is to achieve communication with others, and it is important for reasoning and problem solving (Mcloughlin \& Krakwski, 2001). Surya et al. (2013) defined visual thinking skills as a group of processes, involving of a set of abilities that inspire the student to visual thinking and meditation, and to interpret these images into spoken or written language, and extract information from them.

In the field of educational learning, some researchers have tended to pay attention to identifying visual thinking and to concentrate on visual thinking as skills or abilities that play a significant role in learning and teaching. Yunus (2017) defined it as a mental capacity acquired by the learner, so that it enables him to use the sense of sight in perceiving the meanings and connotations and extracting the information contained in the shapes, pictures, drawings, lines, symbols, and colors, and converting it into a verbal language written or spoken, while easily preserving it in his cognitive structure. Huh (2017) defined it as an analytical process that includes receiving, understanding, and producing visual messages.

It can be inferred that visual thinking is one of the forms of thinking based on the connection between the sense of vision and mental activity aimed at obtaining and interpreting visual stimuli apparent from the external environment, and what these stimuli contain in terms of knowledge, facts and relationships, in light of these previous definitions, therefore, understand, interpret and represent these stimuli, and keep them in his cognitive structure and then express them in his language, and the ability to produce visual messages that express his thoughts.

Visual thinking plays a vital role in instruction learning processes. Ammar and Kabbani (2011) pointed to the importance of visual thinking in the field of developing students' visual language skill, developing the ability to understand visual messages surrounding the educational process members from every side as a result of scientific and technical progress, and the ability to solve problems, by selecting and defining visual concepts, understanding abstract concepts and associated processes, developing students' abilities to make visual comparisons and reaching conclusions easily, and facilitating the development of students' abilities to discover similarities and differences in the visual scene.

The two-sided brain theory suggests that there are two complementary ways of processing information. The first is linear, moving step by step, as the left hemisphere of the brain analyzes the parts that make up the pattern, and the second method works to find the visual-spatial relationships that form this model and this is done in the right half of the brain. There is also a noticeable increase in the activities of the right hemisphere when the person operates tasks that need visual thinking and a marked increase in the activities of the left hemisphere when the person operates tasks that require verbal thinking (Novak \& Feingold, 2008).

Visual thinking plays an imperative part in mathematical problem-solving. several learners do not comprehend how to visually or spatially depict problems and resolve math issues. Visual thinking is an ability, method, and products to construct, view, use, and visualize pictures and drawings on notepaper or use procedural means, explain and express information and thoughts, generate thoughts, and understand math problems (Ummu \& Maryono, 2020).

Students may improve visual thinking by focusing on the shapes, sketches, and images provided in the situation and the actual relationships involved in it, and trying to find meaning for the material they contain (Campbell et al., 1995).

By reviewing the previous literature, the researchers noted that many studies agree on the classification of visual thinking skills, including the study of AlShoubaki (2010), the study of Al-Muqbel and Al Jabr (2016), and Al-Shalwi study (2017) on the description of visual thinking skills as follows:

1. The skill of visual discrimination: it means the student's ability to identify the different or similar shape among a group of presented shapes.

2. The skill of visual perception: It means the student's ability to identify the missing shape after observing changes in a series of shapes. 
3. The skill of third dimension perception: It means the student's ability to define the threedimensional shape resulting from folding a flat shape and installing one of the sides as a basic base for the shape.

4. The skill of spatial visualization: It means the student's ability to imagine the shape that represents the scene (top, front, or side) of a building, or to recognize a model when the view (top, front, and side) is visible to the student.

5. The skill of visual analysis of shapes: It means the student's ability to determine the parts of the main form presented.

Technology provides tools that allow individuals to think visually since computers provide models for us to understand and solve problems (West, 1997). Augmented reality technology has an effective role in developing thinking, especially visual thinking. Several studies have found that students who were taught with augmented reality technology performed significantly better than those who were not taught to them in achievement and visual thinking (Al-Ghamdi, 2020; Al Hilou, 2017; Al-Muqrin, 2020; Al-Salahat, 2019; Osamah et al., 2019; Salama, 2019).

\section{Academic Motivation}

Academic motivation is the inner power stimulating the person's conduct and guiding him towards achieving his desired goal. Such inner power could be generated as a result of some internal and/ or external factors (Aqeel, 2012). The achievement motivation is the relatively constant willingness of the person, according to which the person strives and persists until achieving success, and accordingly feels satisfied, in those situations requiring performance evaluation according to a certain level of excellence (Othman, 2010).

Academic motivation could be considered as a factor activating students, controlling their abilities, and regulating their conduct during educational situations, so that such students could engage more in the educational process. Moreover, the academic motivation enhances students' enthusiasm for studying, satisfies their growth requirements, promotes their persistence throughout various educational situations, and encourage them to exert more efforts to memorize various academic subjects (Mansi, 2003).

Weber (2003) classified motivation into two types: the intrinsic motivation through which the person is engaged in a certain activity or task, which means that it is generated for a certain purpose, and could be realized when the student carries out the task to satisfy his desire or for fun while seeking perfection; and the extrinsic motivation through which the person is engaged in a certain activity or task to achieve a goal connected to external factors, such as achieving fame or attaining praise from peers, teachers or parents. Usually, students with extrinsic motivation focus on achieving performance goals, while students with intrinsic motivation focus on intrinsic qualities and might amend the goals as required to accomplish the task because they enjoy studying (Butler, 2000). Many researchers concluded that academic motivation declines, in particular, when students move from elementary school to middle school, and the academic achievement is declined accordingly (Alspaugh, 2001; Bassi et al., 2007).

Modern technologies, in particular the augmented reality technology, play an effective role in enhancing student motivations. In this regard, the research of $\mathrm{Di}$ Serio et al. (2013) aimed at determining the effectiveness of the augmented reality technology on enhancing student motivations in the Visual Arts Course. This research concluded that the augmented reality technology had an affirmative impact on the motivations of middle school students and demonstrated that confidence and comfort factors attained the highest scores in light of the augmented reality technology. Furthermore, the results of research of Ibarra et al. (2019) demonstrated that $50 \%$ of students who used the augmented reality technology, when dealing with signs and 3D objects, were more enthusiastic and interested when studying mathematics and communication. The results of the research of Sarkar et al. (2020) aimed at developing an augmented reality-based unit for the curriculum of the seventh and the eighth grades to promote student active participation in the classroom while learning lines and angles, demonstrated that the majority of the participants - representing 90.4\% preferred carrying out augmented reality learning activities in pairs more than individually, and there was no significant difference between the motivation scores of the participants of both groups. Furthermore, the research of Valarmathie et al. (2020) proved the effectiveness of the augmented reality technology in enhancing the learning motivation for scientific experiments. Also, many researchers demonstrated that the augmented reality technology had a positive effect on student learning motivation, and the following are some of such researches: Sudirman et al. (2020), ChengChang (2020), Ibáñez et al. (2020), Chen (2019), Chen et al. (2019), Kirikkaya and Başgül (2019), and Estapa and Nadolny (2015).

Given the foregoing, it was clear that the achievement motivation of students has a great role in learning mathematics, as it encourages students to practice various activities for learning purposes, side by side with its role in keeping students motivated till the end of the learning activity, achieving the desired learning goal, and enhancing students till reaching self-satisfaction. Therefore, the current research addressed the use of the augmented reality technology in teaching mathematics and examined its effectiveness in enhancing student achievement motivation in mathematics for middle school students. 


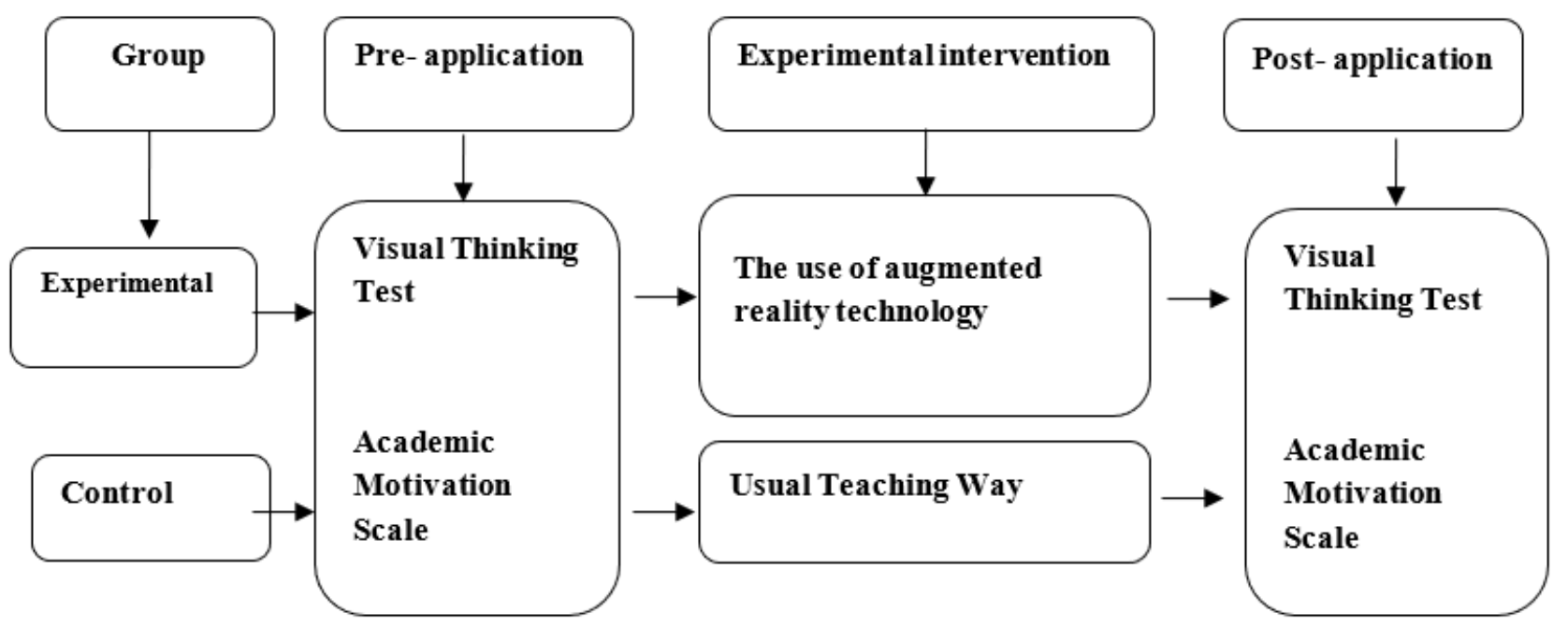

Figure 2. A diagram demonstrating the experimental design of the research

\section{METHODOLOGY}

The current research aimed at examining the effect of the augmented reality technology when teaching mathematics in improving visual thinking skills and academic motivation among middle school students. For such purpose, an experimental approach with a quasiexperimental study design was adopted, and there were two groups: the experimental group and the control group, and Figure 2 demonstrates the experimental design of the research.

\section{Research Community and Sample}

- Research Community: The community of the current research consisted of all regular secondgrade female students enrolled in the middle school, general education schools, Al Khobar, Eastern Province, Kingdom of Saudi Arabia, in 2019/2020 A.D, with a total number of (2742) students, in accordance with the statistical guide of Al Khobar Education Office.

- Research Sample: the research sample consisted of group/ groups of individuals from the original community, which was/were supposed to represent the original community, and such sample was selected in a simple random way, as follows:

The names of all governmental middle schools for girls in Al Khobar, Kingdom of Saudi Arabia, were written on paper scraps, then a scrape representing a school of the research sample was pulled, and accordingly, the Third Middle School for Girls in Dhahran was selected. This school includes 5 classes, so two-second grade classes were selected randomly so that one of them would represent the experimental group. Then, 2/3 class including 38 students was selected to represent the experimental group and 2/1 class including 38 students were selected to represent the

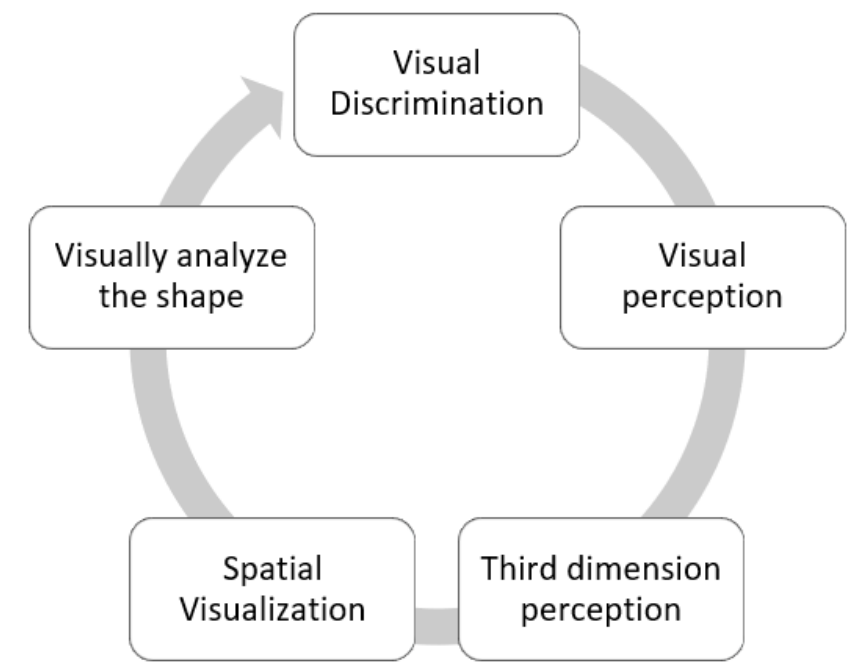

Figure 3. Visual Thinking skills in current research

control group. So, the total sample number was 76 students.

\section{Research Tools}

\section{Visual thinking test}

After reviewing and reading researches addressing visual thinking skills, such as the research of (Al-Maliki, 2016; Elsayed, 2010; Mokely, 2013), the following skills were identified: (visual discrimination of shapes, visual perception of relationships, third dimension perception, spatial visualization, and visual analysis of shapes). These skills were selected due to their appropriateness for the nature of the class (in terms of area and capacity), and each skill was defined for interpretation and measurement; such skills are illustrated in Figure 3.

Multiple-choice questions were formulated for the exam purposes and each question was composed of an introduction and four answer choices including the right choice. So, the exam was composed of 25 multiple-choice questions, so that 5 questions were included under each 
Table 1. Pearson correlation coefficients between each of the visual thinking skills test questions and the total score of the skill to which it belongs

\begin{tabular}{|c|c|c|c|c|c|c|c|c|c|}
\hline \multicolumn{2}{|c|}{ Visual Discrimination } & \multicolumn{2}{|c|}{ Visual perception } & \multicolumn{2}{|c|}{$\begin{array}{l}\text { Third dimension } \\
\text { perception }\end{array}$} & \multicolumn{2}{|c|}{ Spatial Visualization } & \multicolumn{2}{|c|}{$\begin{array}{l}\text { Visually analyze the } \\
\text { shape }\end{array}$} \\
\hline Question & $\begin{array}{c}\text { Pearson } \\
\text { correlation }\end{array}$ & Question & $\begin{array}{c}\text { Pearson } \\
\text { correlation }\end{array}$ & Question & $\begin{array}{c}\text { Pearson } \\
\text { correlation }\end{array}$ & Question & $\begin{array}{c}\text { Pearson } \\
\text { correlation }\end{array}$ & Question & $\begin{array}{c}\text { Pearson } \\
\text { correlation }\end{array}$ \\
\hline 1 & 0.795 ** & 6 & 0.775 ** & 11 & 0.785 ** & 16 & 0.807 ** & 21 & $0.825 * *$ \\
\hline 2 & $0.775 * *$ & 7 & $0.797 * *$ & 12 & $0.813 * *$ & 17 & $0.917 * *$ & 22 & 0.773 ** \\
\hline 3 & $0.749 * *$ & 8 & $0.672 * *$ & 13 & $0.772 * *$ & 18 & $0.784 * *$ & 23 & $0.805 * *$ \\
\hline 4 & $0.807 * *$ & 9 & $0.741 * *$ & 14 & $0.793 * *$ & 19 & $0.845 * *$ & 24 & $0,819 * *$ \\
\hline 5 & $0.764 * *$ & 10 & 0.812 ** & 15 & $0.769 * *$ & 20 & 0.794 ** & 25 & 0.792 ** \\
\hline
\end{tabular}

${ }^{* *}$ Correlation is statistically significant at 0.01

visual thinking skill. The initial version of the visual thinking test was posed to a group of arbiters specialized in mathematics education, to solicit their views concerning the appropriateness of each statement of the visual thinking test for students enrolled in the second grade of the middle school, and the required amendments were made in light of the instructions of arbiters.

Pilot Test: after verifying the validity of the test, the test was implemented to a pilot sample composed of 64 students enrolled in the second grade of the middle school, to determine the required average time. For such purpose, the time spent by the first student completing the test questions and the time spent by the last student completing the test questions were calculated, and then the average of both times was calculated; and accordingly, the time required for the test was estimated at 22 minutes. Moreover, the internal consistency of the visual thinking test was verified through calculating the Pearson Correlation Coefficient to identify to what extent each question of the test was related to the overall score of the skill under which it was included, and Table 1 demonstrates the related results.

Moreover, the overall reliability of the visual thinking test was proved using the Kuder-Richardson formula, and the reliability coefficient was estimated at 0.933 , which confirmed that the visual thinking test had an acceptable degree of reliability and was appropriate for scientific research purposes.

\section{Academic motivation scale}

This scale was aimed at measuring the willingness of the students enrolled in the second grade of the middle school and included in both the experimental and control groups, to perform the duties assigned to them by the mathematics teacher, in mathematics before and after the experiment, to determine the effectiveness of the augmented reality technology in improving the academic motivation.

After reviewing the researches addressing the achievement motivation such as the research of (AlAlwani, 2011; Chen, 2019), the following dimensions were identified: (ambition, perseverance, enjoying
Table 2. Correlation coefficients between each dimension of the motivation achievement scale and the total score of the scale

\begin{tabular}{lcc}
\hline The dimension of the scale & $\begin{array}{c}\text { Correlation } \\
\text { coefficients }\end{array}$ & Sig. \\
\hline Ambition & 0.838 & 0.01 \\
Perseverance & 0.823 & 0.01 \\
Enjoying learning mathematics & 0.851 & 0.01 \\
\hline
\end{tabular}

learning mathematics). These dimensions were selected, in accordance with previous researches due to their appropriateness for middle school students. The statements of the scale were formulated in consistent with the Three Point Likert Scale, so that the responses were (approve, neutral, disagree). The three-point scale was selected due to its clarity and appropriateness for the middle school students. Furthermore, the test instructions were prepared for guiding and instructing students when answering the test. The scale was presented to a group of arbiters specialized in mathematics education, then the required amendments were made in accordance with the views of arbiters.

After verifying the validity of the scale, the scale was implemented to a pilot sample composed of 64 students enrolled in the second grade of the middle school. The time spent by the first student responding to the scale statements and the time spent by the last student responding to the scale statements were calculated, and the average of both times was calculated. Accordingly, the time required to respond to the scale was estimated at 22 minutes.

The internal consistency of the academic motivation scale was verified through calculating the Pearson Correlation Coefficient to identify to what extent each dimension of the scale was related to the overall score of the scale, and Table 2 demonstrates the related results.

Table 2 demonstrates that the values of the correlation coefficients of the dimensions of the academic motivation scale were statistically significant at the significance level of (0.01). Also, the reliability of the academic motivation scale was verified using the Cronbach's Alpha Coefficient, to calculate the reliability of the scale dimensions and overall score, and the results are as demonstrated in Table 3. 
Table 3. Cronbach's alpha coefficients for the dimensions of the motivation achievement scale and the total score of the scale

\begin{tabular}{lcc}
\hline The dimension of the scale & $\begin{array}{c}\text { Items } \\
\text { Number }\end{array}$ & $\begin{array}{c}\text { Cronbach's alpha } \\
\text { coefficients }\end{array}$ \\
\hline Ambition & 8 & 0,831 \\
Perseverance & 8 & 0,854 \\
Enjoy learning mathematics & 8 & 0,876 \\
The total score of the scale & 24 & 0.918 \\
\hline
\end{tabular}

According to Table 3, the overall stability coefficient of the scale was estimated at 0.918, which was considered as an acceptable value, and accordingly the scale was determined as appropriate for scientific research purposes.

\section{Teaching procedures using the augmented reality technology}

\section{Teacher Guide:}

After reviewing the researches addressing the augmented reality technology, such as the research of (Al-Husseini, 2014; Al Shizawya, 2018), the teacher guide was prepared to support the teacher when teaching at the class (measurement: area and volume) using projected augmented reality technology due to its ease of use. The guide included the following elements: (guide objectives - an overview of the concept, characteristics, and advantages of the augmented reality technology - an overview of the augmented reality applications - the teaching timeline of the class topics (measurement: area and volume) - class objectives lesson planning). The lessons were planned in accordance with the four steps identified in the teacher guide for teaching mathematics for the second grade of the middle school, these steps are as follows:

- Focus: demonstrating the basic skills before the lesson, and memorizing previous experiences through the augmented reality activities.

- Teaching: offering the teacher a proposal regarding how to teach the lesson, highlighting the mathematical content of the lesson, and offering some related illustrative examples.

- Training: including various exercises through which the augmented reality technology could be used, and achieving the lesson objectives.

- Evaluation: including questions to verify to what extent students comprehend the concepts introduced in the topic.

When developing the teacher guide, clarification of the media type to be presented through the augmented reality technology when teaching the lesson, such as pictures and videos, was taken into consideration, and also a set of programmers used for developing and introducing the digital content in a proper way, such as

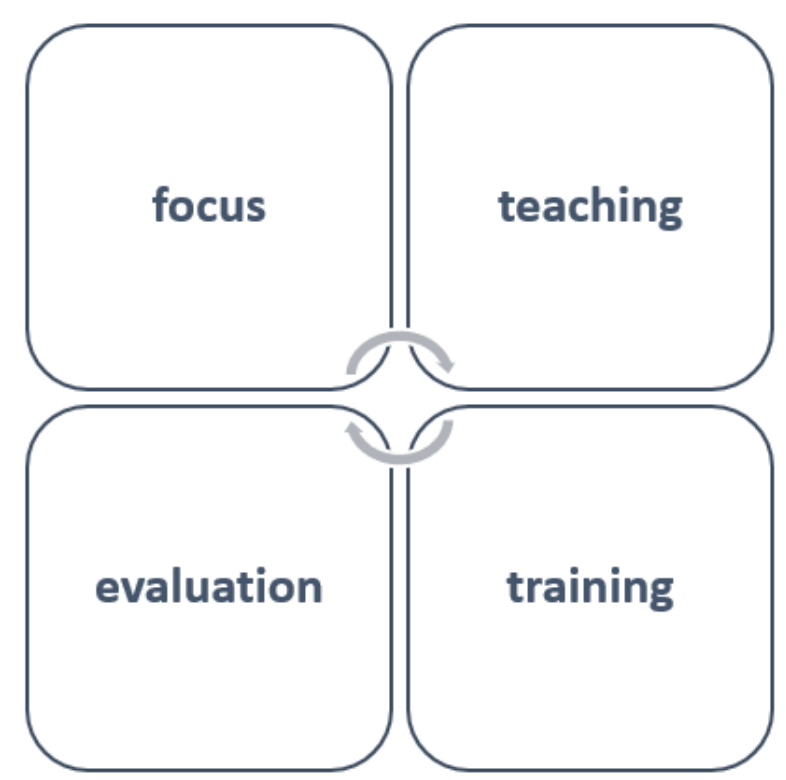

Figure 4. Augmented reality process

PowToon, Paint 3D, iMovie, Adobe Audition, were used.

Student Activity Book: the student activity book composed of two parts:

The first part: a guide instructing the student on how to use the augmented reality applications (Hp RevealZappar), through following the steps illustrated and specified for each application.

The second part: composed of 7 worksheets, one for each lesson, including 20 various activities; and in each activity, the student was required to use an application (Hp Reveal or Zappar) to display the digital content of the required question, and also a blank space was specified for each activity to write the answer.

After completing the development of (the teacher guide, the teacher guide for teaching, and the student activity book), they were presented to a group of arbitrators specialized in mathematics education, to solicit their views concerning the appropriateness of the teacher guide for the augmented reality technology, the linguistic and scientific correctness of the guide, the appropriateness of the activities and worksheets to the level of the students enrolled in the second grade of the middle school, and the appropriateness of the augmented reality technology media proposed for the educational content of the lesson. After reviewing the required amendments, the final version of the guide and the activity book was ready.

\section{RESULTS AND DISCUSSION}

The concluded research results explaining the research questions and the verification of the research hypotheses are explained below: 
Table 4. Independent sample t-test for posttest score

\begin{tabular}{lcccccccc}
\hline Group & $\mathrm{N}$ & Mean & St. Deviation & Df & T- value & $\eta^{2}$ & d & Effect size \\
\hline Control & 38 & 14.16 & 2.91 & \multirow{2}{*}{74} & \multirow{2}{*}{17.76} & \multirow{2}{*}{0.810} & \multirow{2}{*}{4.12} & High \\
Experimental & 38 & 23.42 & 1.37 & & & & & \\
\hline
\end{tabular}

Table 5. Paired-samples t-test of the difference between the means of scores of the experimental group on the posttest and the follow-up test of visual thinking

\begin{tabular}{|c|c|c|c|c|c|c|}
\hline \multirow{3}{*}{ Follow-up test - posttest } & \multicolumn{3}{|c|}{ Paired Differences } & $t$ & $\mathrm{df}$ & Probability \\
\hline & Mean & Std. Deviation & Std. Error Mean & 2086 & 37 & 0044 \\
\hline & 0.211 & 0.622 & 0.101 & 2.000 & Ji & 0.047 \\
\hline
\end{tabular}

\section{Results Related to the Research First Question}

To answer the first question of the research, which provides for: what is the effectiveness of the augmented reality technology on improving visual thinking skills in mathematics among second-grade middle school students? The first hypothesis of the research, which provides for: "There is a statistically significant difference between the mean scores of the experimental group students and the mean scores of the control group students in the post-application of the visual thinking test in mathematics, in favor of the experimental group students", was verified.

To verify the validity of this hypothesis, the arithmetic mean and the standard deviation of the scores attained by both groups were calculated, and the T-test was implemented to appreciate the significance of the difference between the scores of both the experimental and control groups, and Table 4 illustrates the results attained by both the experimental and control groups in the T-test, during the post-application of the visual reasoning test.

Table 4 demonstrates that there was a statistically significant difference at the significance level of (0.01) between the mean scores of the experimental group students and the mean scores of the control group students in the post-application of the visual thinking test, in favor of the experimental group students. Accordingly, the first hypothesis was deemed accepted. The results also indicated that the effect size was significant because the value of $\eta 2$ was greater than 0.8 , as $\mathrm{d}=4.12$ and $\eta 2=0.810$, which means that the total variance of the dependent variable (visual thinking) was attributed to the effect of the independent variable (the augmented reality technology).

The validity of the second hypothesis was tested, which stated that "There is no statistically significant difference between the mean scores of the experimental group in the post and follow up visual thinking test (two months after the completion of the application of the research experiment)". The Paired Samples T Test was used to identify the significance of the difference between the mean scores of the experimental group students in the visual thinking test in the post and follow up measures (two months after the end of the experiment), and Table 5 shows the researchers' findings.

As shown in Table 5, there was no statistically significant difference in the experimental group's mean scores on the post and follow-up visual thinking tests (two months after the research experiment ended), indicating that augmented reality technology continues to be beneficial in promoting visual thinking among the experimental group's students. This is because the use of the augmented reality technology with the experimental group students contributed to enhancing their ability to identify, describe and illustrate shapes in an interactive way, side by side with the possibility of redisplaying for several times as required by the student and according to her ability to learn and the time available inside and outside the classroom, which enhanced the student ability to deal, analyze, visualize and describe shapes. This is consistent with the results of (Osamah et al., 2019), which indicated that amendments could be made through the augmented reality technology to integrate the virtual world with the real world in a single template, thus increasing the coherence and consistency of information displaying and enhancing the student visual thinking ability. Accordingly, the student interaction with the real world could be increased through technical development, and the learner's ability to wander through the real world could be enhanced, as the learner finds himself in his usual environment and has the willingness to explore and learn.

Moreover, the augmented reality technology also enhanced ideas' sequencing and association, representing situations, establishing connections, and exercising on discriminating, analyzing, and extracting ideas from mental images, media, and videos, which helped to develop visual thinking skills. Also, the augmented reality technology allowed the student to practice imagination and visualization, which are both among the important processes required for visual thinking. The result of this hypothesis is consistent with the results of some other researches confirming the effectiveness of the augmented reality technology on improving visual thinking, such as Osamah et al. (2019), Al-Ghamdi (2020), Al-Muqrin (2020), Al-Salahat (2019), Salama (2019), and Al Hilou (2017). 
Table 6. Independent sample t-test for posttest score

\begin{tabular}{lcccccccc}
\hline Group & $\mathrm{N}$ & Mean & St. Deviation & Df & T- value & $\eta^{2}$ & d & Effect size \\
\hline Control & 38 & 44.76 & 6.58 & \multirow{2}{*}{74} & \multirow{2}{*}{18.40} & \multirow{2}{*}{0.821} & \multirow{2}{*}{4.28} & High \\
Experimental & 38 & 66.58 & 3.19 & & & & \\
\hline
\end{tabular}

Table 7. Paired-samples t-test of the difference between the means of scores of the experimental group on the posttest and the follow-up test of academic motivation

\begin{tabular}{lcccccc} 
& \multicolumn{3}{c}{ Paired Differences } & t & Df & Probability \\
\cline { 2 - 5 } Follow-up test - posttest & Mean & Std. Deviation & Std. Error Mean & \multirow{2}{*}{2.91} & \multirow{2}{*}{37} & 0.006 \\
\cline { 2 - 4 } & 0.500 & 1.059 & 0.172 & & & \multirow{2}{*}{0.06}
\end{tabular}

\section{Results Related to the Research Second Question}

To answer the second question of the research, which provides for: what is the effectiveness of augmented reality technology on improving the academic motivation among the second-grade middle school students? The third hypothesis of the research, which provides for: " there is a statistically significant difference between the mean scores of the experimental group students and the mean scores of the control group students in the post-application of the academic motivation scale, in favor of the experimental group students", was verified.

To verify the validity of the hypothesis, the arithmetic mean and the standard deviation of the scores attained by both groups were calculated, and the T-test was implemented to appreciate the significance of the difference between the scores of both the experimental and control groups, and Table 5 illustrates the results attained by both the experimental and control groups in the T-test, in the post-application of the academic motivation scale.

Table 6 demonstrates that there was a statistically significant difference at the significance level of 0.01 between the mean score of the experimental group students and the mean score of the control group students in the post-application of the academic motivation scale, in favor of the experimental group students; accordingly, the second hypothesis deemed accepted. The results also indicated that the effect size was significant because the value of $\eta^{2}$ was greater than 0.8 , as $\mathrm{d}=4028$ and $\eta 2=0.810$, which meant that the total variance of the dependent variable (academic motivation) was attributed to the effect of the independent variable (the augmented reality technology).

The validity of the fourth hypothesis was tested, which stated that "There is no statistically significant difference between the mean scores of the experimental group in the post and follow up academic achievement scale (two months after the completion of the application of the research experiment)". The Paired Samples T Test was used to identify the significance of the difference between the mean scores of the experimental group students in in the post and follow up academic achievement scale (two months after the completion of the application of the research experiment, and Table 7 shows the researchers' findings.

As shown in Table 7, there was no statistically significant difference in the experimental group's mean scores on the post and follow-up academic achievement scale (two months after the research experiment ended), indicating that augmented reality technology continues to be beneficial in promoting academic achievement among the experimental group's students. This could be attributed to the fact that the use of the augmented reality technology with the students of the experimental group took them of the conventional educational situation and engaged them in an interactive environment that promoted their motivation and enhanced them to acquire knowledge. Moreover, students' expression of their ideas through pictures side by side with the atmosphere of freedom and familiarity prevailed at work contributed to the creation of a pleasurable environment providing greater motivation for learning. The result of this hypothesis is consistent with the findings of some other researches, which confirmed the impact of the augmented reality technology in improving motivation for learning, and the following are among these researches: Sudirman et al. (2020), Cheng-Chang (2020), Ibáñez et al. (2020), Chen (2019), Chen et al. (2019), Kirikkaya and Başgül (2019), and Estapa and Nadolny (2015).

\section{RECOMMENDATIONS AND SUGGESTIONS}

In light of the above discussions and the concluded results confirming the impact of the augmented reality technology when teaching mathematics in the development of visual thinking and achievement motivation among middle school students, some recommendations could be offered including holding training courses and workshops for mathematics teachers to train them on the use of the augmented reality technology in teaching mathematics; paying attention to the use of the augmented reality technology in teaching mathematics due to its effective role in attracting learners and promoting their achievement motivation; encouraging teachers to pay attention to the adaptation of the learning environment and providing 
the capabilities required for the use of the augmented reality technology in teaching mathematics in order to stimulate the development of visual thinking skills; and performing whatever required to improve visual thinking skills when teaching mathematics, through the use of various educational technologies enhancing it, such as the augmented reality technology.

The current research also suggests that another similar research should be conducted with a greater focus on identifying the orientations and perceptions of mathematics teachers concerning the augmented reality technology and the training requirements needed for its adoption. Also, it is recommended to conclude further researches to examine student orientations and perceptions regarding the use of the augmented reality technology when teaching mathematics, and it is also recommended to conduct further researches to verify the reliability of the augmented reality technology and its effectiveness in improving other variables other than the visual thinking and motivation among students in various academic stages.

\section{CONCLUSION}

This research aimed at identifying the impact of the use of the augmented reality technology when teaching mathematics in the development of visual thinking and achievement motivation among middle school students in the Kingdom of Saudi Arabia, using the experimental approach and a quasi-experimental design. When analyzing results, it became clear that the students of the experimental group exceeded the students of the control group in both visual thinking and achievement motivation, as the augmented reality technology adapted the actual reality through adding digital features to improve the perception of the learner. Also, the augmented reality technology is equipped with four main components: a camera to capture the target information; markers, which are the target information; mobile phones used for maintaining and processing information when the captured image in the target information is in the form of (markers); and the digital content displayed on the screen when the phone camera can track the markers (Abd Majid et al., 2015).

Moreover, the augmented reality technology offers great flexibility allowing the learner to experiment and explore within the learning environment. Also, the augmented reality technology allows for the development of real learning content (such as books, presentations, and learning tools), in various ways such as adding various graphic elements, 3D images, video screenshots, images, static graphics, and animations according to the individual requirements of learners (Coimbra et al., 2015). Due to these advantages, both visual thinking and motivation achievement were enhanced for the students of the experimental group, which could be attributed to the active learning environment full of various learning resources such as pictures and videos, which was provided by the augmented reality technology, this, in turn, enhanced the cognitive structure of student, developed their visual thinking and motivation for learning and achieved better learning of visual thinking skills. Additionally, the use of the augmented reality technology when presenting the skill side by side with its details achieved better learning than the conventional way and enhanced the development of the visual thinking skills. Both of the researchers suggest conducting other similar researches addressing other educational stages and verifying the impact of the augmented reality technology on student perceptions and orientations in various fields.

Author contributions: All authors have sufficiently contributed to the study, and agreed with the results and conclusions.

Funding: No funding source is reported for this study.

Declaration of interest: No conflict of interest is declared by authors.

\section{REFERENCES}

Abd Majid, N., Mohammed, H., \& Sulaiman, R. (2015). Students' Perception of Mobile Augmented Reality Applications in Learning Computer Organization. Procedia - Social and Behavioral Sciences, 176, 111-116. https:/ / doi.org/10.1016/j.sbspro.2015.01.450

Ahmad, N. N. (2020). Augmented Reality for Learning Mathematics: A Systematic Literature Review. International Journal of Emerging Technologies in Learning, 15(16), 106-122. https://doi.org/10.3991/ ijet.v15i16.14961

Al-Alwani, L. (2011). The effectiveness of concept maps in developing the recognizing of the relationships between mathematical concepts and achievement motivation among middle school students (Unpublished master thesis). Princess Nourah Bint Abdulrahman University.

Al-Ghamdi, I. (2020). The effectiveness of the augmented reality-based teaching strategy in developing mathematical proficiency and visual thinking among middle school students. The Journal of Educational Sciences: King Saud University - College of Education, 32(3), 485-511.

Al Hilou, N. (2017). The effectiveness of teaching a proposed unit in home economics using the mental imagination strategy based on the augmented reality technology, on the development of visual thinking and curiosity among primary school students. Arabic Studies in Education and Psychology: The Association of Arab Educators, 91, 87-150.

Al-Husseini, M. (2014). The effect of using the augmented reality technology in a computer course unit on the achievement and attitude of high school students (Unpublished master thesis). Umm Al-Qura University, Makkah.

Al Laqani, A. \& Al-Jamal, A. (2013). Glossary of educational definition terms in curriculum and teaching methods ( $3^{\text {rd }}$ Ed.). The World of Books. 
Al-Maliki, A. (2016). The effect of a constructive educational program on developing mathematical thinking skills among students enrolled in the second grade of middle school. Journal of Education: Al-Azhar University - Faculty of Education, 1(171), 182-215.

Al-Muqbel, N., \& Al Jabr, J. (2016). Evaluating the science book of the middle school first grade in the light of visual thinking skills. The International Interdisciplinary Journal of Education: Dar Semat for Studies and Research, 5(3), 174-191. https:/ / doi.org/10.12816/0035882

Al Muqrin, I. (2020). The effectiveness of using the augmented reality technology in developing visual thinking skills, during the art education course among female students enrolled in the first grade of the middle school in Riyadh. The Journal of Educational $\mathcal{E}$ Psychological Sciences: University of Bahrain - Scientific Publishing Center, 21(2), 271-308.

Al Salahat, O. (2019). The effectiveness of using augmented reality in developing visual thinking skills and achievement level in mathematics among students enrolled in the basic seventh grade (Unpublished PhD thesis), The World Islamic Science \& Education University, Amman.

Al Shalawi, A. (2017). The applicability of visual thinking skills during the sixth-grade science course. The International Interdisciplinary Journal of Education: Dar Semat for Studies and Research, 6(3), 243-251.

Al Shizawya, L. (2018). The effect of teaching based on the augmented reality technology on the acquisition of concepts of polygons and circle, and in spatial reasoning among sixth grade students (Unpublished master thesis). Sultan Qaboos University.

Al Shobaki, F. (2010). The effect of adopting the systemic approach for the development of the concepts and skills of visual thinking in physics among the eleventh-grade female students (Unpublished master thesis). The Islamic University of Gaza.

Alimat, M., \& Abu Jalalah, S. (2011). Contemporary general teaching methods. Al-Falah Library for Publishing and Distribution.

Alspaugh, J. W. (2001). School Size as a Factor in Financing Small Rural Schools. Rural educator, 23(1), 9-13.

Ammar, M., \& Kabani, N. (2011). Visual thinking in light of educational technology. The New University House.

Anderson, E. \& Liarokapis, F. (2010). Using augmented reality as medium to assist teaching in higher education. Coventry University. https://doi.org/10.2312/eged. 20101010

Aqeel, I. (2012). The effect of learning dimensions, for Marzano, on the achievement and motivation in learning mathematics among seventh grade students. The Journal of Al-Azhar University of Gaza, 14(2), 121150.

Azuma, R. T. (1997). A survey of augmented reality. Presence: Teleoperators $\mathcal{E}$ Virtual Environments, 6(4), 355-385. https:/ / doi.org/10.1162/ pres.1997.6.4.355

Azuma, R., Baillot, Y., Behringer, R., Feiner, S., Julier, S., \& MacIntyre, B. (2001). Recent advances in augmented reality. IEEE Computer Graphics and Applications, Computer Graphics and Applications, IEEE, IEEE Comput. Grap. Appl, 21(6), 34-47. https://doi.org/ 10.1109/38.963459

Bacca, J., Baldiris, S., Fabregat, R., Graf, S. \& Kinshuk, (2014). Augmented Reality Trends in Education: A Systematic Review of Research and Applications. Educational Technology E Society, 17(4), 133-149.

Baker, E. J., Bakar, J. A. A., \& Zulkifli, A. N. (2020). Elements of Engagement in Promoting Social Acceptance of Mobile Augmented Reality Application. International Journal of Interactive Mobile Technologies, 14(17), 66-78. https:/ / doi.org/10.3991/ijim.v14i17.16555

Barreira, J., Bessa, M., Pereira, L. C., Adao, T., Peres, E., \& Magalhaes, L. (2012). MOW: Augmented reality game to learn words in different languages: Case study: Learning English names of animals in elementary school. 7th Iberian Conference on Information Systems and Technologies (CISTI 2012), Information Systems and Technologies (CISTI), 2012 7th Iberian Conference On, 1-6.

Bassi, M., Steca, P., Delle Fave, A., \& Caprara, G. V. (2007). Academic self-efficacy beliefs and quality of experience in learning. Journal of Youth and Adolescence, 36(3), 301-312. https://doi.org/10.1007/s10964-0069069-y

Butler, R. (2000). Chapter 7 - What learners want to know: The role of achievement goals in shaping information seeking, learning, and interest. Intrinsic and Extrinsic Motivation, 161-194. https://doi.org/10.1016/B978012619070-0/50029-5

Cai, S., Liu, E., Shen, Y., Liu, C., Li, S., \& Shen, Y. (2020). Probability learning in mathematics using augmented reality: impact on student's learning gains and attitudes. Interactive Learning Environments, 28(5), 560573. https:/ / doi.org/10.1080/10494820.2019.1696839

Campbell, K., Collis, K., \& Watson, J. (1995). Visual Processing during Mathematical Problem Solving. Educational Studies in Mathematics, 28(2), 177-194. https:/ / doi.org/10.1007/BF01295792

Chen, C.-H., Huang, C.-Y., \& Chou, Y.-Y. (2019). Effects of augmented reality-based multidimensional concept maps on students' learning achievement, motivation and acceptance. Universal Access in the Information Society, 18(2), 257-268. https://doi.org/10.1007/ s10209-017-0595-Z

Chen, Y. (2019). Effect of Mobile Augmented Reality on Learning Performance, Motivation, and Math Anxiety in a Math Course. Journal of Educational Computing Research, 57(7), 1695-1722. https://doi.org/10.1177/ 0735633119854036

Cheng-Chang, T. (2020). The Effects of Augmented Reality to Motivation and Performance in EFL Vocabulary Learning. International Journal of Instruction, 13(4), 9871000. https:/ / doi.org/10.29333/iji.2020.13460a

Coimbra, T., Cardoso, T., \& Mateus, A. (2015). Augmented Reality: An Enhancer for Higher Education Students in Math's Learning? Procedia Computer Science, 67, 332339. https:/ / doi.org/10.1016/j.procs.2015.09.277 
Di Serio, Á., Ibáñez, M., \& Kloos, C. D. (2013). Impact of an augmented reality system on students' motivation for a visual art course. Computers and Education, 68, 586596. https:// doi.org/10.1016/j.compedu.2012.03.002

Diaza, C., Hincapiéb, M., \& Morenoc, G. (2015). How the Type of Content in Educative Augmented Reality Application Affects the Learning Experience? Procedia Computer Science, 75, 205-212. https:/ / doi.org/10.1016 /j.procs.2015.12.239

Elsayed, A. (2010). A proposed program in mathematics in accordance with the theory of brain structure-based learning theory for the development of academic achievement and some thinking skills among middle school students (Unpublished PhD thesis). Faculty of Education, Suez Canal University.

Estapa, A., \& Nadolny, L. (2015). The Effect of an Augmented Reality Enhanced Mathematics Lesson on Student Achievement and Motivation. Journal of STEM Education: Innovations \& Research, 16(3), 40-48.

Glockner, H., Jannek, K., Mahn, J., \& Theis, B. (2014). Augmented reality in logistics: Changing the way we see logistics - a DHL perspective.

Hsiao, H.-S., Chang, C.-S., Lin, C.-Y., \& Wang, Y.-Z. (2016). Weather observers: a manipulative augmented reality system for weather simulations at home, in the classroom, and at a museum. Interactive Learning Environments, 24(1), 205-223. https:// doi.org/10.1080 /10494820.2013.834829

Huh, K. (2017). Visual thinking strategies and creativity in English education. Indian Journal of science and technology, 9(S1), 1-6. https://doi.org/10.17485/ijst /2016/v9iS1/109885

Ibáñez, M. B., Uriarte Portillo, A., Zatarain Cabada, R., \& Barrón, M. L. (2020). Impact of augmented reality technology on academic achievement and motivation of students from public and private Mexican schools. A case study in a middle-school geometry course. Computers $\mathcal{E}$ Education, 145, 1-9. https://doi.org/ 10.1016/j.compedu.2019.103734

Ibarra, M., Gomez, E., Barzola, B., Castillo, M., Ibanez, V., \& Quispe, R. (2019). Improving Student's Learning Motivation in Schools using Augmented Reality. 2019 XIV Latin American Conference on Learning Technologies (LACLO), Learning Technologies (LACLO), 2019 XIV Latin American Conference on, LACLO, 259-264. https:/ / doi.org/10.1109/LACLO49268.2019.00051

Ivanova, M., \& Ivanov, G. (2011). Enhancement of learning and teaching in computer graphics through marker augmented reality technology. International Journal on New Computer Architectures and Their Applications (IJNCAA), 1(1), 176-184.

Kerawalla, L., Luckin, R., Seljeflot, S., \& Woolard, A. (2006). Making it real: exploring the potential of augmented reality for teaching primary school science. Virtual Reality, 10(3/4), 163-174. https://doi.org/10.1007/ s10055-006-0036-4

Kirikkaya, E. B., \& Başgül, M. Ş. (2019). The effect of the use of augmented reality applications on the academic success and motivation of 7 th grade students. Journal of Baltic Science Education, 18(3), 362-378. https://doi.org/10.33225/jbse/19.18.362

Klopfer, E., \& Squire K. (2008). Environmental DetectivesThe Development of an Augmented Reality Platform for Environmental Simulations. Educational Technology Research and Development, 56(2), 203-228. https:/ / doi.org/10.1007/s11423-007-9037-6

Larsen, Y., Bogner, F., Buchhlz, H., \& Brosda, C. (2011). Evaluation of a portable and interactive augmented reality learning system by teachers and students, Open Classroom Conference Augmented Reality in Education Ellinogermaniki Agogi (pp. 41-50), Athens, Greece.

Lee, K. (2012). Augmented reality in education and training. TechTrends: Linking research and practice to improve learning, 56(2), 13-21. https://doi.org/10.1007/ s11528-012-0559-3

Liou, H., Yang, S., Chen, S., \& Tarng, W. (2017). The influences of the 2D image-based augmented reality and virtual reality on student learning. Journal of Educational Technology E Society, 20(3), 110-121.

Mansi, M. (2003). Learning: Concept - Models - Applications. The Anglo Egyptian Bookshop.

McLoughlin, C., \& Krakowski, K. (2001, September 23-26). Technological tools for visual thinking: What does the research tell us? Paper presented at the Apple University Consortium Academic and Developers Conference, James Cook University, Townsville, Queensland, Australia.

Mokely, F. (2013). The level of Spatial Visualization among middle school students (Master thesis). Umm Al-Qura University.

Muhammad, F. (2016). The effect of using interactive classroom in teaching engineering on the development of academic achievement, visual thinking skills and emotional satisfaction among middle school students. Journal of Pedagogical Mathematics, 19(2), 84-146.

National Council of Teachers of Mathematics. (2008). The role of technology in the teaching and learning of mathematics: A position of the national council of teachers of mathematics. http://www.nctm.org/about/ content.aspx?id=14233

Nofal, K. (2010). Virtual reality technology and its educational applications (1 ${ }^{\text {st }}$ Ed.). Dar Al-Manahej for Publishing \& Distribution.

Novak, M., \& Feingold, L. (2008). Left brain, right brain: Different approaches to retaining and sharing organizational knowledge, digital government institute. https:/ / silo.tips/ download/left-brain-right-braindifferent-approaches-to-retaining-and-sharingorganizatio

Osamah, M., Zyad, A., Ali, B., \& Wafa, A. (2019). Effect of augmented reality and simulation on the achievement of mathematics and visual thinking among students. International Journal of Emerging Technologies in Learning (IJET), 14(18), 164-185. https://doi.org/ 10.3991/ijet.v14i18.10748 
Othman, M. (2010). Professional pressures and their relationship to achievement motivation of civil protection agents (Master thesis). University of Mentouri Brothers Constantine, Algeria.

Patkar, R., Singh, P., \& Birji, S. (2013). Maker Based Augmented Reality Using Android Os. Journal of advanced research in computer science and software engineering, 3(5), 46-69.

Perez-Lopez, D., \& Contero, M. (2013). Delivering educational multimedia contents through an augmented reality application: A case study on its impact on knowledge acquisition and retention. Turkish Online Journal of Educational Technology TOJET, 12(4), 19-28.

Rattanarungrot, S., White, M., \& Newbury, P. (2014). A mobile service oriented multiple object tracking augmented reality architecture for education and learning experiences. International Association for Development of the Information Society.

Salamah, A. (2019). The effectiveness of adopting the augmented reality and electronic mind maps for the development of visual thinking skills in life science subject among students enrolled in the eleventh grade in Gaza (Unpublished master thesis). The Islamic University (Gaza), Gaza.

Sarkar, P., Pillai, J. S., \& Kadam, K. (2020). Learners' approaches, motivation and patterns of problemsolving on lines and angles in geometry using augmented reality. Smart Learning Environments, 7(1), 1-23. https:/ / doi.org/10.1186/s40561-020-00124-9

Shelton, B. (2002). Augmented reality and education: Current project and the potential for classroom learning. New Horizons for Learning, 9(1), 1-20.

Sudirman, S., Mellawaty, M., Poopy, Y., \& Rully, I. (2020). Integrating local wisdom forms in augmented reality application: Impact attitudes, motivations and understanding of geometry of pre-service mathematics teachers'. International Journal of Interactive Mobile Technologies, 14(11), 91-106. https:/ / doi.org/10.3991/ijim.v14i11.12183
Surya, E., Sabandar, J., Kusumah, Y. S., \& Darhim. (2013). Improving of junior high school visual thinking representation ability in mathematical problem solving by CTL. Indonesian Mathematical Society Journal on Mathematics Education, 4(1), 113-126. https:/ / doi.org/10.22342/jme.4.1.568.113-126

The Ministry of Education. (2016). Education and The Saudi Vision 2030. https://www.moe.gov.sa/ar/Pages/ vision2030.aspx

Ummu, S., \& Maryono, M. (2020). Students' visual thinking ability in solving the integral problem. Journal of Research and Advances in Mathematics Education, 5(2), 175-186. https://doi.org/10.23917/jramathedu.v5i2. 10286

Valarmathie, G., Juliana, A., \& Abdul, N. (2020). Development of the MARPEX App embedding the mobile augmented reality factors for learning motivation in science experiments. International Journal of Interactive Mobile Technologies, 14(17), 155166. https:/ / doi.org/10.3991/ijim.v14i17.16641

Weber, K. (2003). The relationship of interest to internal and external motivation. Communication Research Reports, 20(4), 376-383. https://doi.org/10.1080/0882409030 9388837

West, T. G. (1997). In the mind's eye. Prometheus Books.

Yuen, S., Yaoyuneyong, G., \& Johnson, K. (2011). Augmented reality: An overview and five directions for AR in education. Journal of Educational Technology Development $\mathcal{E}$ Exchange, 4(1), 119-140. https:/ / doi.org /10.18785/jetde.0401.10

Yunus, E. (2017). A proposed program based on visual thinking skills for the development of scientific drawing skills and raising awareness regarding its importance among female student teachers in biology. The Egyptian Journal of Scientific Education, 20(3), 117149.

\section{http://www.ejmste.com}

